\title{
Shifting support for inequitable gender norms among young Indian men to reduce HIV risk and partner violence
}

\author{
Ravi K. Verma \\ Population Council \\ Vaishali Sharma Mahendra \\ Population Council \\ Julie Pulerwitz \\ Population Council \\ Sujata Khandekar \\ Gary Barker
}

See next page for additional authors

Follow this and additional works at: https://knowledgecommons.popcouncil.org/departments_sbsr-hiv

Part of the Family, Life Course, and Society Commons, Gender and Sexuality Commons, and the International Public Health Commons

How does access to this work benefit you? Let us know!

\section{Recommended Citation}

Verma, Ravi K., Vaishali Sharma Mahendra, Julie Pulerwitz, Sujata Khandekar, Gary Barker, P. Fulpagare, and S.K. Singh. 2006. "Shifting support for inequitable gender norms among young Indian men to reduce HIV risk and partner violence," Horizons Research Summary. New Delhi: Population Council. 


\section{Authors}

Ravi K. Verma, Vaishali Sharma Mahendra, Julie Pulerwitz, Sujata Khandekar, Gary Barker, P. Fulpagare, and S.K. Singh 


\section{Hgrizons}

\section{SHIFTINg SUPPORT FOR INEQUITABLE Gender Norms AMONg Young INDIAN Men to Reduce HIV Risk AND PARTNER VIOLENCE}

A participatory, group intervention to promote gender equity, which was adapted from a successful program in Brazil, was piloted with young men in Mumbai. Compared to baseline, intervention particpants decreased their support for inequitable gender norms and reported less sexual harassment, and there were trends toward less risky behaviors. A larger study to test the impact of the intervention is now ongoing.

I ndia accounts for the second largest population of people living with HIV/AIDS (5.1 million) (NACO 2005b). It is estimated that almost half of new HIV infections occur in young men below age 30 (NACO 2005a). While there are multiple factors influencing young men's HIV risk in India, an important one that is receiving increasing attention is early socialization about masculinity. Young men in India mature and develop in a male-dominated context, with little contact with female peers and virtually no sex education (Verma and Mahendra 2004). In this context, most boys develop a sense of masculinity characterized by male dominance in the sexual arena as well as many other areas. It has been argued that chal-

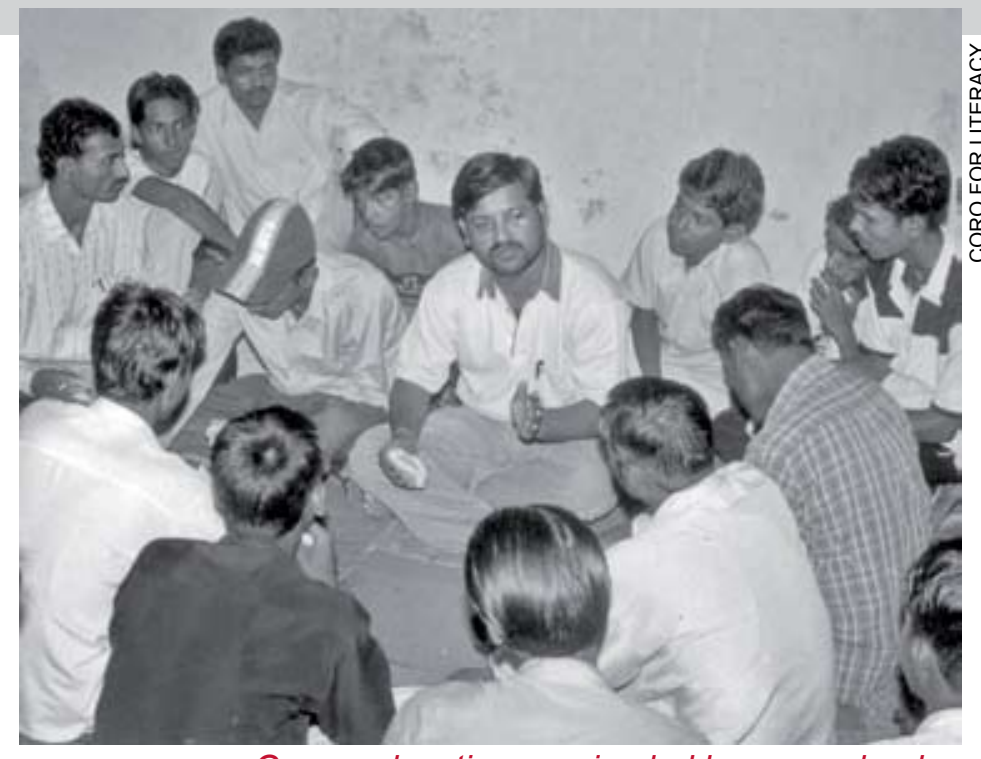

Group education session led by a peer leader. lenging these views of masculinity whereby men have more power than women is essential to promoting sexual health and to reducing both young men's and young women's vulnerability to HIV (Weiss, Wheelan, and Rao Gupta 2000).

Although there is increasing awareness of the role norms that encourage gender inequality play in fostering HIV risk behaviors and partner violence, few studies have attempted to influence these norms and measure changes in support for them among young men exposed to an intervention. In response to this gap, the Horizons Program; CORO for Literacy, an India-based NGO; and Instituto 
PROMUNDO, a Brazilian NGO, conducted operations research to examine the impact on young men of promoting gender equity as part of an HIV prevention program.

Specifically, the research addressed the following questions:

- How is masculinity understood and expressed by young men in India?

- How can gender equitable norms and behaviours, including those related to violence and HIV/STI risk reduction, be promoted among young men?

- Will this type of intervention be feasible and acceptable in the Indian context?

- What impact will the intervention have on attitudes toward gender norms, and HIV and other risk behaviors?

- How can change in attitudes toward gender norms be measured?

\section{Methodology}

Formative research was conducted with young men in low-income communities in Mumbai, India, on the links between gender and masculinity, sexuality, and health risk. Peer leaders from the communities were intensively trained on data collection techniques. These leaders, under the guidance of the researchers, conducted a total of 51 interviews with young men aged 16 to 24 years. In addition, four focus group discussions were conducted with NGO leaders, political and religious leaders, and young women from the same communities.

Intervention activities for young men were then developed/adapted. Peer leaders were trained to facilitate group education sessions, which involved 126 young men over a six month period. The feasibility and acceptability, as well as the impact of the intervention, were measured. The intervention team monitored attendance at the sessions and kept track of the themes discussed during the activities. An independent research team conducted pre- and post-intervention surveys with the young men $(\mathrm{n}=107$ and $\mathrm{n}=92$, respectively). Qualitative interviews were also conducted with a subset of young men after selected sessions $(n=16)$, with those who had dropped out of the intervention $(\mathrm{n}=11)$, and with the intervention facilitators $(n=4)$. Observations of selected intervention activities also took place.

Changes in attitudes toward gender norms were measured using the 24-item Gender-equitable Men (GEM) Scale, which was developed in Brazil (Pulerwitz and Barker forthcoming). The scale consists of a list of statements about men's and women's roles related to domestic work and childcare, sexuality and sexual relationships, reproductive health and disease prevention, and intimate partner violence, as well as attitudes toward homosexuality and close relationships with other men.

As part of the formative research, GEM Scale items were pre-tested and discussed with a sample of young men from Mumbai $(n=65)$, to confirm that the items were relevant and clear in the Indian context. At baseline, the GEM Scale was highly internally consistent (alpha $>.86$ ).

Other outcomes measured included knowledge of HIV and AIDS, sexual harassment, physical and sexual violence, condom use, and number of sexual partners.

\section{Concepts of Masculinity: Findings from the Formative Research}

The formative research highlighted how concepts of masculinity influence a variety of domains addressed in the GEM Scale (e.g., sexuality and sexual relationships, harassment and violence, and disease prevention). 
When asked about masculinity, the young men participating in the formative research described the physical and social attributes of a "real man," or asli mard in Hindi. Overall, a real man was characterized as someone who is handsome, strong, muscular, and virile. Sexual potency was seen as an important way for men to establish superiority and control over women. Young men also said that a real man should not have "feminine mannerisms," or baila, characteristic of homosexuals. Informants used a variety of demeaning terms to describe men who have sex with other men.

Being dominant was another important social quality associated with being a real man. Respondents often highlighted physical and verbal aggression carried out against other men, either individually or as part of a group, as important evidence of masculinity. As one respondent noted, "Real men lead and win fights and quarrels.” But aggression to prove manhood was also directed at womenwives, girlfriends, and acquaintances. Informants often referred to women as chhav (an "item" or "object"), indicating that women were possessions of men. To demonstrate sexual power, men commonly noticed coercive behaviors, including touching, jostling, making derogatory comments, whistling, and harassing women in public places. Coercive activities also included sexual acts such as forced kissing and forced intercourse with female partners.

Socially, a real man was also reported to be someone who takes care of his children, wife, parents, and siblings. Throughout the interviews, responsibility to family was a frequently cited positive attribute of a real man, such as in these two examples: "He should earn well and look after his family" and "He should be sincere and loyal to his wife...."

It is evident from the formative data that condom use did not figure prominently in the lifestyles of the young men. Sex often happened in a hurry, and there was little thought given to using a condom.
.... when somebody is sexually excited why would

he spend time in taking out a condom and putting it on his penis?

Also, girlfriends and wives, as well as other men, including a specific group of men who dress in women's clothing (called hijras), were not seen as potential carriers of disease, and therefore condoms were never used with them, even though the young men themselves may have had multiple partners.

... why should I use condoms during sexual relations with my own wife or girlfriend... it is not needed....

...during sex with hijras one does not need condom....

An exception to the lack of condom use was with sex workers. There was an enormous amount of fear of AIDS among the young men who associated AIDS with sex workers. Therefore, condom use was common with sex workers.

\section{The Yari-Dosti Intervention: Pro- moting Gender-equitable Norms and Behaviours}

Based on results from the formative research, as well as drawing on experiences addressing gender equity in other cultural contexts, a behavior change intervention targeted to young men was developed and piloted. The program attempts to stimulate critical thinking about the gender norms that promote risky behavior and to create support for those that promote care and communication. A gender-equitable man was defined in this project as one who (1) supports relationships based on respect, equality, and intimacy rather than on sexual conquest, (2) is or seeks to be an involved domestic partner and father, both in terms of childcare and household activities, (3) assumes or shares with his partner the responsibility for reproductive health and disease prevention, (4) 


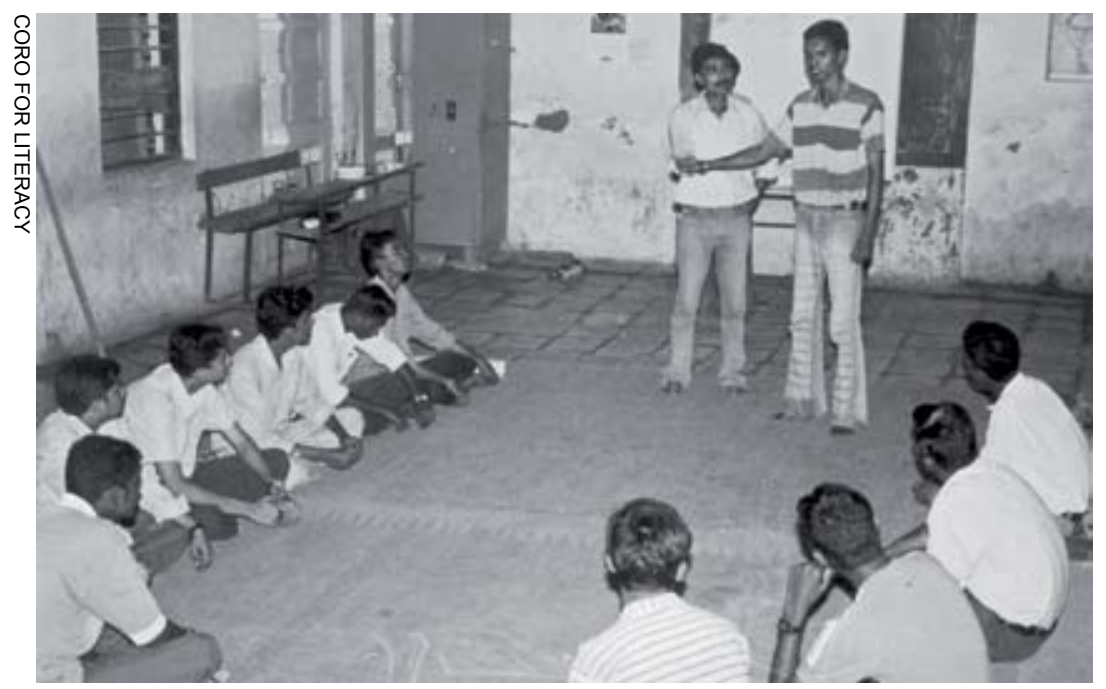

A participant presents his views on gender issues to his peers.
Peer leaders, who were mainly drawn from the group that participated in the formative research, underwent a two-week training program to strengthen their gender and HIV-related knowledge and facilitation skills. They then recruited four groups of young men from the community to participate in the intervention. The young men were recruited from vocational training groups; political, cultural, and religious youth groups; youth on the street; and through a network of the peer leaders' friends. The 126 participants thus recruited were divided into four groups of 30 to 35 participants each. The intervention started with an intensive week of group educational activities, facilitated by both peer leaders and adult gender "specialists," followed by two to three-hour sessions every week, led by peer leaders only, for a duration of six months.

Of the 126 young men aged 18 to 29 who participated in the group educational activities, 107 completed the pre-test questionnaire. At baseline, the mean age of respondents was 21 . Almost threefourths (72 percent) were single, 19 percent had a current girlfriend, and 9 percent were married. A little more than half of the young men (56 percent) had completed 11 years or more of formal education. Most of the young men earned less than Rs. 2,000 (US\$45) per month.

\section{Key Findings}

\section{At baseline, the young men largely supported inequitable gender norms.}

Responses to selected GEM Scale items are included in Table 1. In general, a substantial proportion supported inequitable gender norms. As an example from the sexuality and sexual relationships domain, almost half (42 percent) reported agreement with the statement that "It is the man who decides what type of sex to have." In the violence domain, over a third (36 percent) agreed 
with the statement "A woman should tolerate violence in order to keep her family together." With regards to domestic life and caregiving, almost two-thirds of respondents (63 percent) agreed that "Changing diapers, giving the kids a bath, and feeding the kids are the mother's responsibility." Over half (55 percent) reported that "Women who carry condoms on them are easy," which was part of the reproductive health and disease prevention domain. And finally, turning to homophobia, over half (55 percent) reported "I would never have a gay friend."

At the same time, there was substantial agreement with a number of equitable gender norms. For example, 85 percent indicated that they agreed with the statement "A couple should decide together if they want to have children."

\section{Men who reported partner violence were more supportive of inequitable gender norms.}

All 24 items were combined into the GEM Scale. The responses to the 24 GEM Scale items were scored using a three-point scale; the possible range of scores was 24 to 72 . A lower score indicated greater support for inequitable gender norms.

Mean GEM Scale scores were not associated with age, income, or education. However, married participants were more supportive of inequitable gender norms than unmarried participants $(\mathrm{p}<.05)$. Regarding key risk outcomes, those who reported physical violence against a partner (e.g., wife, girlfriend) over the last three months were more supportive of inequitable gender norms $(p=.05)$. In

\section{Table 1 GEM Scale item responses at baseline}

\section{Sexuality and sexual relationships}

It is the man who decides what type of sex to have.

Men are always ready to have sex.

A man needs other women, even if things with his wife are fine.

\section{Violence}

There are times when a woman deserves to be beaten.

If someone insults me, I will defend my reputation, with force if I have to.

A woman should tolerate violence in order to keep her family together.

\section{Domestic life and caregiving}

A woman's most important role is to take care of her home and cook for her family.

Changing diapers, giving the kids a bath, and feeding the kids are the mother's responsibility.

A man should have the final word about decisions in his home.

Reproductive health and disease prevention

Women who carry condoms on them are easy.

It is a woman's responsibility to avoid getting pregnant.

I would be outraged if my wife asked me to use a condom.

\section{Homophobia and relations with other men}

I would never have a gay friend.

It disgusts me when I see a man acting like a woman. 
addition, those who consumed alcohol regularly were more likely to support inequitable gender norms $(\mathrm{p}=.05)$.

\section{Participants moved from denying that gen- der norms mattered to challenging these norms and behaviors.}

Monitoring data indicate that almost all of the young men recruited for the project consistently participated in the activities. Both the peer leaders and the participants indicated that the young men were greatly interested in the topic areas, as it was often their first opportunity to discuss these issues openly. They particularly liked having the chance to communicate about these issues with other men. Participants were initially most interested in factual/biological information (e.g., the human body, sex, HIV), but over time found the sessions on gender-related attitudes, sexual violence, and power dynamics between men and women engaging. When asked about the effects of participation, some of the young men noted that the sessions had changed their understanding of love, sexuality, and masculinity. As one participant expressed:

I was earlier thinking that condom use reduces sexual pleasure. Now I feel that those who think so have not understood what sexuality is. It's not only penetrative sex but every part of our body can give us sexual pleasure. Understanding between partners is the main thing.

Another participant reflected on the importance of the education sessions in opening up communication with his wife:

\section{...I was about to divorce my wife due to misun-} derstandings. These sessions restrained me from doing that.

A third participant reflected on gender norms that he was previously not consciously aware of but had come to recognize: ...the larger environment around us provides justification for violence and coercion. We see men beating their partners/wives and there is a tendency to emulate them....

The peer leaders - from their perspective as facilitators of the sessions-observed that there was a process of change through which the young men transitioned over time. In general, the young men began by (a) denying that inequitable gender norms existed or that they could be linked to risk for both the young men and their partners, and then transitioned to (b) gradually accepting that these norms existed, (c) realizing that change would be worthwhile, and (d) exploring ways in which they and those around them could challenge these norms and related behaviors.

Some sessions resulted in heated discussions and debates among the participants. This was particularly prevalent during exercises where participants role-played stigmatized groups such as sex workers and during exercises that discussed intimate partner violence. Facilitators needed appropriate skills to handle conflicts that erupted during the sessions, and this was part of their original training.

\section{After the intervention, participants reported less support for inequitable gender norms.}

There were substantial positive changes in the GEM Scale items at post-test, and most of the changes were statistically significant $(\mathrm{p}<.05)$. For example, the proportion of young men who agreed that "There are times when a woman deserves to be beaten" decreased from 31 percent at baseline to 14 percent at endline. Respondents who agreed that "Women who carry condoms on them are easy" decreased from 55 percent at baseline to 19 percent at endline. Agreement with the statement "It is the man who decides what type of sex to have" decreased from 42 percent at baseline to 20 percent at endline. And, young men who supported the statement "A man should have the final 
word about decisions in his home" decreased from 34 percent at baseline to 11 percent at endline.

When combined, the overall GEM Scale scores also showed significant positive changes. Responses from the group of young men who completed both the baseline and endline survey were compared $(n=92)$. The mean GEM Scale score significantly increased (from 43.4 at baseline to 45.0 at endline; $\mathrm{p}<.01$ ), indicating that the group as a whole was less supportive of inequitable gender norms.

To permit another interpretation of the findings, the possible GEM Scale scores were split into three equal categories. These categories were termed "least equitable" (lower range scores: 24-40), "moderately equitable" (middle range scores: 41-57), and "most equitable" (higher range scores: 58-72). Data shown in Figure 1 indicate that there was a significant positive shift $(p<.01)$ from the least equitable category before the intervention to the moderately equitable category after it.

These positive changes were by and large similar across sociodemographic characteristics, although there were some non-significant trends toward younger men changing more substantially than older men, and young men with less education changing more substantially than those with more education.

\section{Decreases in harassment and risk behav- ior were noted post-intervention.}

There were some indications post-intervention of a reduction in violence and other risk and prevention behaviors. Responses from young men who completed both the baseline and endline survey $(\mathrm{n}=92)$ were analyzed to ensure that the same sample was compared over time. As shown in Figure 2, self-reported harassment of girls over the past three months (referred to as "eve teasing" in India) significantly declined $(\mathrm{p}<.001)$. Reported physical violence against any sexual partner, married or unmarried, over the past three months declined from 51 percent $(18 / 35)$ to 39 percent $(10 / 26)$.

There was also a trend toward increasing condom use at last sex with any sexual partner (from 46 percent $(16 / 35)$ to 58 percent $(15 / 26)$. In addition, there was a small reduction in the number of young men who reported sex with any non-marital partner in the last three months (from 29 to 23).

\section{Discussion}

The predominant view of masculinity and men's roles in sexual and romantic relationships espoused by the young men at baseline was one of entitlement and dominance. The gender-focused intervention attempted to promote positive norms such as responsibility, caring, and respect for one's partner and women in general.

The intervention was implemented successfully, and almost all of the young men recruited for the project consistently participated in the activities. Both the peer leaders and the participants indicated that the young men were very interested in the topic areas, as it was often their first opportunity to discuss these issues openly. Compared to baseline, participants decreased their suppport for inequitable gender norms and reported less sexual harassment, and there were trends toward less risky
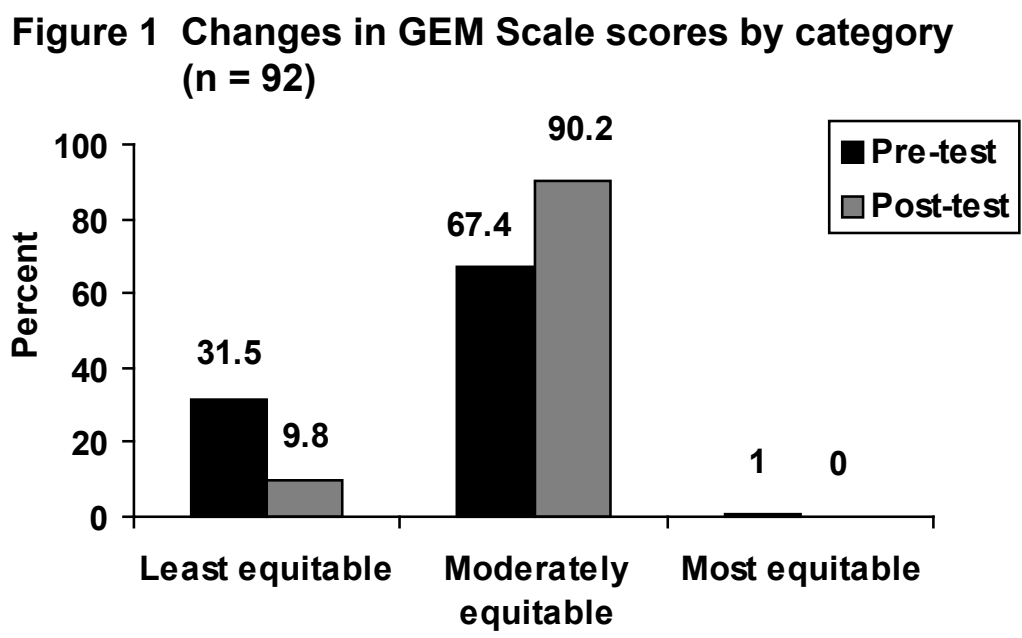
Figure 2 Change in harassment of girls $(n=92)$

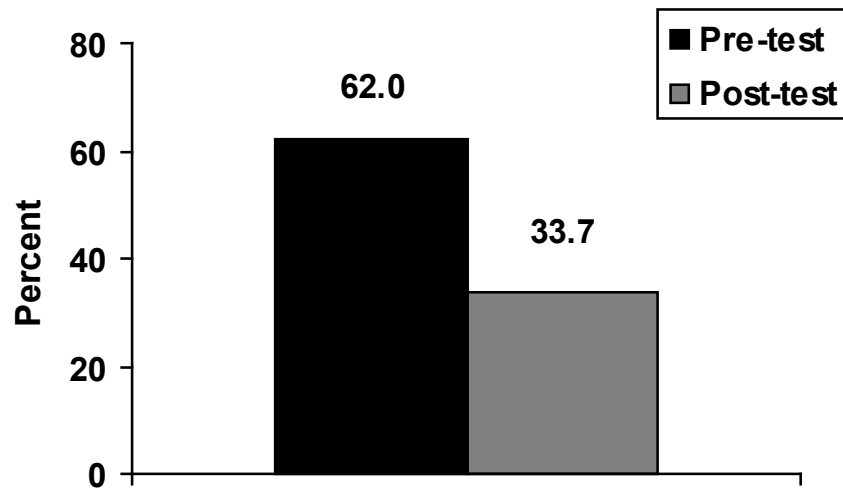

Harassed any girl

behaviors. Additional research on a larger scale is needed to support these findings.

Based on the experiences generated during the pilot intervention, a larger evaluation of the group education intervention is currently in progress with over 1,000 young men. The intervention is being implemented in both urban Mumbai and rural settings in the state of Uttar Pradesh. In some sites, group education activities are combined with a community-based and gender-focused "lifestyle" social marketing campaign, to reinforce the gender equitable and HIV prevention messages from the group education sessions. The campaign promotes a gender sensitive and violence-free lifestyle for young men in the community. Young men actively participated in the development and implementation of the campaign. With a tag line of "soch sahi mard vahi" ("Real men have the right attitude"), the campaign consists of street plays, posters, pamphlets, banners, and a service and information booth. Intervention results are forthcoming in 2006. .

\section{References}

National AIDS Control Organization (NACO). 2004. Annual Report 2003-4. New Delhi: Ministry of Health and Family Welfare. 2005a. http://www.nacoonline.org/vasco/indianscene/ overv.htm. Accessed 13 March 2006.

2005b. "Facts and figures: Monthly updates on AIDS (January 2005)," http://www.nacoonline.org/facts_reportjan.htm. Accessed 13 March 2006.

Pulerwitz, Julie and Gary Barker. "Measuring equitable gender norms for HIV/STI and violence prevention with young men: Development of the GEM Scale," Men and Masculinities forthcoming.

Pulerwitz, Julie et al. 2006. "Promoting more gender-equitable norms and behaviors among young men as an HIV/AIDS prevention strategy," Horizons Final Report. Washington, DC: Population Council.

Verma, Ravi and Vaishali Mahendra. 2004. "Construction of masculinity in India: A gender and sexual health perspective," Indian Journal of Family Welfare 50:71-78.

Weiss, E., D. Whelan, and G. Rao Gupta. 2000. "Gender, sexuality and HIV: Making a difference in the lives of young women in developing countries," Sexual Relationship Therapy 15(3):233-45.

\section{Acknowledgments}

Principal study investigators included Ravi K. Verma and Vaishali Mahendra, Horizons/Population Council; Julie Pulerwitz, Horizons/ PATH; Sujata Khandekar, CORO for Literacy; Gary Barker, Instituto PROMUNDO; and P. Fulpagare and S.K. Singh, International Institute for Population Studies.

The authors would like to acknowledge the contributions made by Mahendra Rokade, Vilas Sarmalkar, and the CORO team in the adaptation and implementation of the pilot intervention. Many thanks to Ellen Weiss, Hena Khan, and Jennifer Redner for their assistance with reviewing and preparing this report.

Suggested citation: Verma, Ravi K., Julie Pulerwitz, Vaishali Mahendra, Sujata Khandekar, Gary Barker, P. Fulpagare, and S.K. Singh. 2006. "Shifting support for inequitable gender norms among young Indian men to reduce HIV risk and partner violence," Horizons Research Summary. New Delhi: Population Council.

\section{Hprizons $\lambda$}

Population Council/Horizons

53, Lodi Estate

New Delhi 110003

INDIA
1 Population Council

Tel: 2461-0913/0914

2464-9047

$2469-9747 / 9748$

Fax: 2461-0912

horizons-india@popcouncil.org

www.popcouncil.org/horizons
This publication was made possible through support provided by the President's Emergency Plan for AIDS Relief through the Office of HIV/ AIDS, Bureau of Global Health, U.S. Agency for International Development (USAID), under the terms of Award No. HRN-A-00-97-00012-00. The opinions expressed herein are those of the authors and do not necessarily reflect the views of USAID.
๑ 2006 The Population Council Inc.

This document may be reproduced in whole or in part without permission of the Population Council provided full source citation is given and the reproduction is not for commercial purposes. 